\title{
ESTUDOS EM CULTURA ESCRITA E ESCOLARIZAÇÃO: UMA PROPOSIÇÃO DE SIMPÓSIO ENTRE IDEÁRIOS TEÓRICOS DE BASE HISTÓRICO-CULTURAL NA BUSCA DE CAMINHOS METODOLÓGICOS PARA PESQUISAS EM LINGUÍSTICA APLICADA
}

\author{
ESTUDIOS EN CULTURA ESCRITA Y ESCOLARIZACIÓN: UNA PROPUESTA DE SIMPOSIO ENTRE \\ IDEARIOS TEÓRICOS DE BASE HISTÓRICO-CULTURAL EN LA BÚSQUEDA DE CAMINOS \\ METODOLÓGICOS PARA INVESTIGACIONES EN LINGÜÍSTICA APLICADA
}
STUDIES IN WRITTEN CULTURE AND SCHOOLING: A COMBINATION OF THEORETICAL APPROACHES FROM THE HISTORIC-CULTURAL FRAMEWORK AS METHODOLOGICAL PATHS FOR RESEARCH IN APPLIED LINGUISTICS

\author{
Mary Elizabeth Cerutti-Rizzatti* \\ Suziane Mossmann \\ Josa Coelho da Silva Irigoite
}

Universidade Federal de Santa Catarina - UFSC, Florinópolis, BR

\begin{abstract}
RESUMO: Este artigo tematiza o delineamento de caminho metodológico-analítico para estudos no campo da cultura escrita e da escolarização, tendo como objetivo a proposição desse mesmo delineamento a partir de um simpósio conceitual entre ideários de base histórico-cultural: conceitos vigotskianos, bakhtinianos e dos estudos do letramento são agenciados para proposição de diagrama em integração, ressignificando encaminhamentos analíticos de Hamilton (2000), diagrama potencialmente instrumentador de processos analíticos em pesquisas acerca da cultura escrita. Trata-se de uma busca de caminhos analíticos para estudos fundamentados nesses três grandes ideários teóricos, os quais, em seus construtos não contêm detalhamentos dessa ordem em razão das especificidades que os constituem como ciência ou literatura.
\end{abstract}

PALAVRAS-CHAVE: cultura escrita; ideário histórico-cultural; metodologia de pesquisa; Linguística Aplicada.

RESUMEN: En este artículo tematizase el delineamiento del camino metodológico-analítico para estudios en el campo de la cultura escrita y de la escolarización, teniendo como objetivo la proposición de ese mismo delineamiento a partir de un simposio conceptual de la literacidad son agenciados para proposición de diagrama en interacción, resignificando encaminamientos analíticos de Hamilton (2000), diagrama potencialmente instrumentador de procesos analíticos en investigaciones acerca de la cultura escrita. Tratase de una búsqueda de caminos analíticos para estudios fundamentados en esos tres grandes idearios teóricos, los cuales, en su constructo no contienen detalles de esa orden en razón de las especificidades que os constituyen como ciencia o literatura. PALABRAS-CLAVE: cultura escrita; ideario histórico-cultural; metodología de la investigación; Lingüística Aplicada.

ABSTRACT: This article focuses on the design of analytical methodological path for studies in the field of literacy and mother tongue teaching and learning practices. We aim to propose this design from a conceptual symposium between ideas of cultural and historical basis. We work with vigotskian, bakhtinian and literacies studies concepts, and we propose an interaction diagram, resignifying Hamilton (2000) analytical referrals. This diagram serves for analytical processes in research on the written culture. We are searching analytical paths to studies based on these three theories, which in their constructs don't contain this kind of information due to their particularities that constitute them as science or as literature.

KEYWORDS: written culture; historical and cultural approach; research methodology; Applied Linguistics.

\section{INTRODUÇÃO}

Estudos acerca dos processos de educação em língua materna contemporaneamente têm se estruturado a partir do ideário histórico-cultural, que se assenta na concepção de sujeito historicizado, o que implica sensibilidade à inserção social e cultural específica de homens e mulheres, jovens e crianças, universalizados em sua condição ontológica de seres humanos. Convergentemente com essa concepção de sujeito, esse ideário ancora-se em uma concepção de língua como objeto social, objeto concebido, aqui, no plano filosófico de objeto de conhecimento que se materializa em práticas sociais de usos da língua as quais instituem relações interpessoais entre esses mesmos sujeitos historicizados.

\footnotetext{
* Pesquisadoras do Núcleo de Estudos em Linguística Aplicada - NELA/UFSC. Email: ma.rizzatti@gmail.com.
} 
O construto sob o qual se assenta esse ideário - sobremodo tais concepções de sujeito e de língua - tem materializado proposições teóricas no campo da psicologia da linguagem - a exemplo do pensamento vigotskiano -, da filosofia da linguagem - a exemplo do amplo espectro do pensamento do Círculo de Bakhtin -, e da antropologia da linguagem - a exemplo dos estudos do letramento. Compreendendo que essas construções teóricas, ainda que não tenham como foco os processos de escolarização, são fecundas para interpretar tais processos em sua conhecida complexidade, entendemos urgentes proposições que, a partir do zelo em evitar interpenetrações conceituais indevidas, tanto quanto a partir do zelo de evitar modelizações universalizantes, ofereçam aporte para atividades de pesquisa que tenham a cultura escrita como mote, especialmente no que respeita ao imbricamento entre cultura escrita e processos de escolarização.

Dando corpo a esse entendimento, propomos, neste artigo, aproximações entre esses espectros teóricos, na busca de ensaiar possibilidades de encontro entre encaminhamentos do campo da psicologia da linguagem, da filosofia da linguagem e da antropologia da linguagem - olhares convergentes sob o ponto de vista de uma compreensão epistemológica de base histórico-cultural -, os quais não nos oferecem modelos analíticos efetivos, mas possivelmente viabilizem proposições nessa ordem, desde que, em nossa compreensão, sejam salvaguardadas suas especificidades de origem.

\section{UMA PROPOSIÇÃO DE SIMPÓSIO ENTRE PERSPECTIVAS CONCEITUAIS ${ }^{1}$ EM RELAÇÕES QUE ENTENDEMOS DIALÓGICAS}

Apropriando-nos do olhar de Ponzio (2010), que concebe a linguagem como o lugar de encontro entre sujeitos historicizados, estendemos, aqui, a noção de encontro para o campo conceitual de que nos ocuparemos à frente. Entendemos a lógica do encontro como ancorada na perspectiva da historicidade: os sujeitos levam-se para o encontro, carreando consigo suas vivências, seus valores, sua constitutividade na alteridade; e, nesse encontro com o outro, responsivamente incidem sobre ele e se deixam incidir pela outridade, provocando deslocamentos e movências na historicidade erigida até ali, no evento único e irrepetível que é cada encontro em si mesmo. Esse olhar para a subjetividade que se constitui no encontro remete a um movimento de deslocamento para proposto por Geraldi (2010a, p. 34-35), que escreve: "É eleição de um outro lugar. E o lugar privilegiado é o da interlocução tomada como espaço de produção de linguagem e de constituição dos sujeitos [...] a linguagem fulcra-se como evento, faz-se na história e tem existência real no momento singular da interação verbal”.

Ousamos, nesta discussão, propor o encontro entre perspectivas conceituais distintas - o que nomearemos, aqui, à luz de Faraco (2007), de simpósio -, mas que viabilizam tal encontro em nome de compartilhamentos e não isomorfias - no que tange a concepções sobre subjetividade e linguagem, tal qual mencionamos na introdução. Para que haja o encontro, há que haver quem o promova. E entendemos que as discussões acadêmicas são território fecundo para o agendamento desses episódios. Eis o risco, tanto quanto eis a necessidade de enfrentá-lo.

E de que encontro tratamos? Coloquemos neste simpósio conceitual, em primeira mão, a concepção vigotskiana de linguagem como instrumento psicológico de mediação simbólica que faculta o movimento de apropriação intrassubjetiva da cultura a partir das relações intersubjetivas com um interlocutor mais experiente, fazendo derivar, dessa relação, novos delineamentos na Zona de Desenvolvimento Real dos sujeitos historicizados (VIGOTSKI, 2000 [1978]). Eis a história, tão cara ao ideário vigotskiano, compreendida como as transformações pelas quais passam os sujeitos em razão da materialização das relações sociais, tanto quanto as transformações que esses sujeitos, agora transformados, imprimem no meio social. Não se trata do tempo concebido em si mesmo - o presente, o passado e o futuro; trata-se daquilo que se constrói entre o ontem e o hoje, entre o hoje e o amanhã, historicizações que dependem da linguagem porque se erigem a partir das relações intersubjetivas por ela engendradas.

Façamos participarem desse simpósio, também, concepções fundantes do ideário bakhtiniano, com destaque à alteridade/outridade. A força da presença do outro no Círculo de Bakhtin é marcante em todos os diferentes

\footnotetext{
${ }^{1}$ Não nos ocupamos, nesta seção, de verticalizar os conceitos teóricos a que fazemos menção porque os entendemos de amplo domínio na esfera acadêmica. Nosso propósito é proceder tão somente à evocação desses conceitos, supondo o agenciamento de conhecimentos prévios do leitor acerca de sua notória complexidade.
} 
desdobramentos conceituais que têm lugar no âmbito das publicações do Círculo, sobretudo em Volóshinov $^{2}$ (2009 [1929]), e sua imperiosa concepção de linguagem como atividade social historicizada, a qual se aproxima estreitamente do pensamento vigotskiano. Trata-se, aqui, de um encontro que nos sossega promover sobretudo em razão de considerações de Brandist (2012), para quem Volóshinov e Vigostki foram coetâneos no Instituto de Línguas de Leningrado. Escreve Volóshinov (2009 [1929], p. 149):

[...] el enunciado más primitivo de um hombre, realizado por un organismo singular, se organiza fuera de éste, en las condiciones extraorgánicas del médio social. El enunciado en cuanto tal es plenamente el producto de uma interacción social, tanto de la más imediata, determinada por la situación social de la conversación, como de la más amplia, definida por todo el conjunto de condiciones de una coletividade hablante dada.

Geraldi, Benites e Fichtner (2007) também propõem aproximações entre o pensamento vigotskiamo e o pensamento do Círculo de Bakhtin. Dentre outras convergências, consoante esses autores, assim como em Vigotski (2000 [1978]), para Bakhtin

[...] a linguagem é constitutiva da consciência e de toda a atividade mental. O sujeito constitui-se nas interações de que participa. Bakhtin estuda a relação da consciência com o sistema de signos, e também passa pela questão das atividades mentais do eu e das atividades mentais do nós. (GERALDI; BENITES; FICHTNER, 2007, p. 183).

Paralelamente à centralidade atribuída à linguagem, a aproximação entre ambos os pensadores dar-se-ia no que respeita ao compromisso com o futuro.

Ao conceber a linguagem como lugar de uma ação reguladora do psiquismo, ou tomá-la como atividade constitutiva do sujeito, tanto Bakhtin quanto Vigotski enfrentam, de forma radical, a questão da correlação entre sujeito e sociedade, entre o que já está dado e o que está por ser alcançado, entre passado e futuro. (GERALDI; BENITES; FICHTNER, 2007, p. 143, grifos no original).

Importa, ainda, nessa discussão considerar que o encontro entre o eu e o outro se dá no tempo e no espaço, situadamente, o que nos remete ao conceito bakhtiniano de cronotopo, tanto quanto, evidentemente, nos remete à noção de esfera da atividade humana. À luz do ideário bakhtiniano, arriscamos entender que os encontros de que tratamos aqui implicam relações cronotópicas, dada a indissolubilidade entre as dimensões temporais e espaciais, isso porque indicadores temporais transparecem no espaço, do mesmo modo que a espacialidade se reveste de sentido e é mensurada com o tempo (BAKHTIN, 1998 [1975]).

No ideário bakhtiniano, o imbricamento entre tempo e espaço instaura-se em um processo em contínua formação, uma vez que se situa no campo do acontecimento. Esse olhar para o tempo como movimento de transformação nos faz transcender as dimensões de ontem, hoje e amanhã, tal qual já mencionamos, para atentar ao que acontece entre o ontem e o hoje e entre o hoje e o amanhã. Eis, em nossa compreensão, a transformação de que trata Bakhtin (2003 [1979]), movida pelo tempo, a qual demanda espacialidade; necessariamente, o encontro entre o eu e o outro dá-se nessa mesma espacialidade temporalizada e, por implicação, historicizada.

As séries espaciais e temporais dos destinos e das vidas dos homens se combinam de modo peculiar, complicando-se e concretizando-se pelas distâncias sociais, que não são superadas. Este é o ponto do enlace e o lugar onde se realizam os acontecimentos. Parece que o tempo se derrama no espaço e flui por ele (formando os caminhos) [… (BAKHTIN, 1998 [1975], p. 350)

Importa, também, para as finalidades desta discussão, a compreensão de que não nos enunciamos em um vazio histórico, nem tampouco nos enunciamos na condição adâmica de sujeitos cognitivos. Enunciamo-nos no e para o simpósio universal (FARACO, 2007) de que fazemos parte. Enunciamo-nos, enfim, por causa dos encontros anteriores e também por causa dos encontros atuais e na perspectiva dos encontros futuros. Eis-nos como seres historicizados que se fazem no âmbito da cultura, da sociedade e, portanto, da história; e que se fazem porque compõem a e dispõem da linguagem.

\footnotetext{
${ }^{2}$ Optamos por referenciar a tradução em espanhol, em razão de ser assinada apenas por Volóshinov, dado entendermos tratar-se dessa autoria especificamente.
} 
Entendemos impossível tratar de cultura escrita sem aludir aos estudos do letramento, convidamos, enfim, para esse simpósio, o campo conceitual dessas teorizações, não tomados na perigosa dimensão categorial que justifica adjetivações ad infinitum e que, em nossa compreensão, tende a gaseificar o conceito, tal qual adverte Geraldi (s.d.) ${ }^{3}$. Tomemo-lo nas relações ecológicas (BARTON, 1994) que entendemos fundamentais entre práticas de letramento (STREET, 1988) e eventos de letramento (HEATH, 2001 [1982]), mas enfatizemos a dimensão socioeconômica nas relações entre ambos os conceitos, porque entendemos que as discussões de poder (McLAREN, 1987) implicam fortemente aquela dimensão e, tal qual adverte Britto (2012), lidar com a cultura escrita implica lidar com acessibilidades. Sob essa perspectiva, evocando Kalman (2003), trata-se de uma reflexão sobre relações entre disponibilidade e acessibilidade dos/aos bens culturais que implicam a modalidade escrita da língua. Nesse embate, discussões sobre modelo autônomo e modelo ideológico de letramento revelam-se nodais (STREET, 1984). Enfim, nesse convite ao simpósio, teorizações de Hamilton (2000) que encaminham questões metodológico-procedimentais são de capital importância na discussão que empreendemos. Voltaremos ao simpósio em proposição metodológico-procedimental à frente; antes, porém, façamos uma breve discussão sobre identidade, conceito concebido, aqui, já como emanação inicial do simpósio que nos arvoramos propor.

\section{SIMPÓSIO CONCEITUAL E IMPLICAÇÕES DO CONCEITO DE IDENTIDADE}

Entendemos que discussões acerca de cultura escrita, com enfoque na escolarização, com base no encontro que propomos neste artigo em se tratando de perspectivas conceituais advindas dos campos da psicologia da linguagem, da filosofia da linguagem e da antropologia da linguagem, requerem de nós um olhar sobre a questão da identidade. Refletir acerca desse conceito, porém, à luz desse mesmo ideário, traz consigo a impossibilidade de lidar com o estudo da identidade tomado em si mesmo; importa forçosamente discutir tal conceito na relação dialógica entre identidade e alteridade. Não nos parece possível, com base em concepções de sujeito e de língua tal qual mencionamos anteriormente - desincumbindo-nos de detalhá-las dada sua condição de temas amplamente conhecidos na academia -, empreender um processo de discussão de identidade assentado na individualidade ou que a tenha como origem, o que tributamos a comportamentos subjetivistas. Só podemos fazê-lo na perspectiva do encontro entre o eu e o outro.

Trata-se, pois, de fugir de discussões que tomem o sujeito como multifacetado em sua individualidade, para assumir reflexões que considerem sua constituição como necessariamente movente porque consolidada exatamente nas movências das relações sociais que esse mesmo sujeito estabelece na história entre o ontem e o hoje e entre o hoje e o amanhã. Assim, entendemos impossível empreender essa discussão sob o enfoque de sujeitos que assumem múltiplas identidades, porque compreendemos que o percurso é de natureza distinta: são os encontros que incidem sobre as representações identitárias individuais; assim, a discussão não pode partir do sujeito em sua individualidade, a exemplo do que fazem abordagens contemporâneas ${ }^{4}$; precisa considerar a identidade na relação dialógica com a alteridade, o encontro da outra palavra com $a$ palavra outra (PONZIO, 2010).

A palavra enquanto ato singular e responsável [...] vive na relação de alteridade como relação de diferença não indiferente. Trata-se da palavra como evento irrepetível que, enquanto tal, subtrai-se à indiferença de um sujeito cognoscente, a uma consciência abstrata, a uma visão teorética. E se subtrai justamente pela não indiferença que consiste, de um lado, na responsável participação que essa já requer, na sua própria forma, no seu dizer além do conteúdo, no seu dito, daquele ao qual se dirige de modo único, irrepetível e insubstituível. (PONZIO, 2010, p. 32).

Sob essa perspectiva, denegamos a fluidez, a gaseificação das identidades como origem da discussão. A origem, em nossa compreensão, é a relação com o outro, na qual se gestam as movências. Entendemos, porém, haver, sim, estabilidades identitárias, embora essas estabilidades sejam sempre relativas e sujeitas a tais constantes movências. Trata-se de estabilidades que se justificam em nome da historicidade - haver

\footnotetext{
${ }^{3}$ Ousamos pospor teorizações de João Wanderley Geraldi a teorizações sobre o fenômeno do letramento porque entendemos que a crítica do autor (GERALDI [s.d.]) a estudos nesse campo é endereçada à gaseificação do conceito e não à lógica do conceito em si mesmo. Compartilhamos com o teor da crítica de Geraldi (CERUTTI-RIZZATTI, 2012) e temos nos colocado em favor da compreensão do conceito de letramento como ecologia, tal qual propõe Barton (1994), concebendo que esse olhar dá conta da multiplicidade de usos da escrita, dispensando adjetivações ad infinitum ao conceito ou pluralizações exacerbadas.

${ }^{4}$ Tais quais, em boa medida, são as reflexões de Stuart Hall (2002) e Zygmunt Bauman (2006).
} 
história implica haver ancoragens, e âncoras estão constantemente sujeitas a novos pontos de fixidez, mas corporificam tais pontos de fixidez, ainda que temporários. Negar ancoragens, em nossa compreensão, implica negar, em alguma medida, historicidades. Por outro lado assumir estabilizações não significa, agora em nenhuma medida, advogar em nome de cristalizações e petrificações, porque o movimento da vida, nas relações intersubjetivas, incide constantemente sobre a constitutividade dos homens - as âncoras não são pilastras cimentadas exatamente porque conferem segurança na consciência da iminência da mobilidade. Trata-se, em última instância, de olhar a subjetividade como constituída e não como instituída (GERALDI, 2010a), nem como gaseificada; erigida na Babel - templo das instabilidades - e não na interação pentecostal - harmonização de estabilidades plenificadas - que caracteriza as relações humanas mediadas pela linguagem (PONZIO, 2010). De todo modo, Babel só está aí porque Pentecostes também está. Acerca disso, Ponzio (2010, p. 19) escreve:

Viver juntos está entre Babel e Pentecostes. Não é fácil porque é necessário liberar-se do preconceito segundo o qual tudo seria mais fácil, tudo daria certo e tudo procederia em harmonia se o assujeitamento que a gramática pretende realizar sobre o falar se tornasse verdade, se efetivamente existisse uma gramática universal ou, pelo menos, uma língua nacional unitária, fixa e disponível que requeresse somente o esforço de aprendê-la. Enfim, o preconceito segundo o qual Babel é a maldição e Pentecostes, um milagre.

Interessa-nos, assim, discutir identidade na alteridade, no movimento entre Babel e Pentecostes, fazendo-o à luz do simpósio conceitual que propomos neste artigo, porque nos toca olhar relações humanas situadas no encontro que tem lugar nas diferentes esferas da atividade humana nas quais a cultura escrita se impõe de modo mais efetivo ou menos efetivo. "Como temos distintas histórias de relações com os outros, vamos construindo nossas consciências com diferentes palavras que internalizamos e que funcionam como contrapalavras na construção dos sentidos do que vivemos, vemos, ouvimos, lemos. São essas histórias que nos fazem únicos e “irrepetíveis”' (GERALDI, 2010b, p. 115).

Esses desdobramentos são fecundos em se tratando do imbricamento do qual deriva este artigo: cultura escrita com foco na escolarização, dada nossa disposição de estudar os processos de escolarização como encontros entre distintas vivências com a escrita, entre ancoragens mais convergentes ou menos convergentes entre si (IVANIC, 1998; LILLIS, 2001), do que decorre um enquadre mais para Babel ou mais para Pentecostes (PONZIO, 2010).

Ensaiemos uma maior precisão: em se tratando dos processos de escolarização, nos quais a cultura escrita tem espaço sacrossanto - dada a condição da escola de principal agência de letramento (KLEIMAN, 2001 [1995]), sobretudo nos entornos de vulnerabilidade social que são de nosso mais flagrante interesse no núcleo de pesquisas de que fazemos parte, tanto quanto dado seu compromisso com a horizontalização das vivências dos sujeitos (KALANTIZIS; COPE, 2006) e, ainda, dada a compreensão de que a escola não é lugar para ensinar o que já se sabe (BRITTO, 2012) -, a constituição dos alunos como sujeitos históricos confere-lhes especificidades em se tratando das representações de mundo acerca dos usos da modalidade escrita da língua: são sujeitos historicizados que carreiam para o encontro mediado pela língua suas vivências e seus valores. Assim, "A linguagem, enquanto processo de constituição da subjetividade, marca as trajetórias individuais de sujeitos que se fazem sociais também pela língua que compartilham” (GERALDI, 2010b, p. 123).

Se evocarmos o conceito de ecologia com que Barton (1994) lida acerca do o fenômeno do letramento e que já mencionamos aqui, entenderemos que os alunos chegam à escola, assim como os acadêmicos chegam à universidade, trazendo consigo, para o encontro com o interlocutor mais experiente (VIGOTSKI, 2000 [1978]), nos processos de ensino (DUARTE, 2004), suas práticas de letramento (STREET, 1988), as quais lhes facultam a condição de protagonismo efetivo - inserção em - ou de mera presença física - mobilidade em/circulação por - nos eventos de letramento (HEATH, 2001 [1982]) que têm lugar nessas esferas de escolarização, considerada a relação de sustentabilidade que ambos os conceitos - práticas e eventos mantêm entre si (HAMILTON, 2000).

Essa reflexão nos leva para discussões de identidade na alteridade. Importa, aqui, remissão a Kramsch (1998) e suas teorizações sobre as condições de insider versus outsider que caracterizam as relações intersubjetivas nas diferentes esferas da atividade humana. A condição de insider, segundo a autora, demanda que o sujeito se reconheça como membro daquele grupo, tanto quanto que os outros o reconheçam como tal. Da mesma forma, a condição de outsider implica igual movimento: o sujeito reconhecer-se como 
não membro do grupo, tanto quanto os membros do grupo em questão não o legitimarem como tal. Eis o delineamento da identidade na relação com a outridade. Entendemos, no entanto, que essas relações não podem ser tomadas em uma perspectiva dicotômica - ser ou não ser aprioristicamente; devem ser compreendidas e estudadas à luz da concepção de continuum, do ir-e-vir, das movências, considerando ancoragens identitárias sempre temporárias, tanto quanto movimentos de deslocamento das âncoras, nas busca de novos pontos temporários de fixidez.

Essa, em nossa compreensão, é uma discussão de efetivo interesse em se tratando dos processos de escolarização, a nosso ver incumbidos não de ampliar a mobilidade/circulação dos sujeitos nas diferentes esferas da atividade humana, mas de contribuir para uma efetiva inserção nessas mesmas esferas. Polemizamos, pois, os conceitos de mobilidade/circulação, porque entendendo que, para ambos, não é requerida do sujeito efetivamente a condição de insider ou de aproximação dessa condição. Mover-se e circular em/por determinada esfera pode não significar compartilhamentos efetivos de vivências, de valores, de historicidades. Não raro, alunos e acadêmicos circulam e se movem pelas esferas escolar e acadêmica, mas não se reconhecem e não são reconhecidos como membros efetivos delas e não parecem provar de um movimento de mudanças de pontos de fixidez em suas ancoragens - movimento de que estaria incumbida a escola -, rumo a um processo gradual de inserção efetiva. Eis os inúmeros casos de evasão, de insucesso, de não pertencimento, muitas vezes escamoteados propositadamente em nome de posturas tecnoburocráticas que se alimentam de indicadores oficiais massivos de escolarização em nível nacional, tanto quanto escamoteados em performances acadêmicas mimetizadas em nome da manutenção de determinados cursos e dos recortes mercadológicos de inúmeras instituições de ensino superior no país.

O simpósio conceitual que propusemos na primeira seção deste artigo reverbera na discussão de identidade a que procedemos nesta segunda seção. Sejamos mais explícitas: entendemos que discutir relações entre cultura escrita e escolarização implica considerar questões de identidade/outridade pelas razões já mencionadas. Fazer isso requer, em nossa compreensão, evocar conceitos bakhtinianos de alteridade e dialogismo. Esses conceitos, no entanto, pela sua natureza linguístico-filosófica, parecem não dar conta de explicitudes mais efetivas em se tratando da imersão na cultura escrita, o que toca o universo antropológico tão caro aos estudos do letramento, os quais são precisos em discutir relações entre ser participante de determinado evento em que a escrita está presente e ter vivido experiências que facultam ao sujeito protagonismo nessa participação; ou não. Esse ideário de base linguístico-antropológica, por sua vez, parece não dar conta de uma questão cara ao pensamento vigotskiano: a apropriação intrassubjetiva de representações culturais nas relações intersubjetivas, olhar de base da psicologia da linguagem de fundamentação vigotskiana. Assim, reiterando a concepção de que vemos compartilhamentos e não isomorfias nas concepções de língua e de sujeito desses três construtos, entendemos que estudar como os sujeitos estabelecem relações intersubjetivas nos processos de escolarização, identificando-se mais efetivamente com as proposições das esferas escolar e acadêmica ou entendendo-se como verdadeiros outsideres nesses mesmos espaços no que respeita à cultura escrita, exige um olhar fundado na filosofia da linguagem, na psicologia da linguagem e na antropologia da linguagem, fazendo-o em uma face que seja cara a esses percursos teóricos: neste caso, a preocupação com um sujeito situado no tempo e no espaço, em relação com o outro por meio [da modalidade escrita] da língua, processo que lhe faculta movências em suas representações de mundo e em sua constituição identitária.

\section{O SIMPÓSIO CONCEITUAL E AS IMPLICAÇÕES DE IDENTIDADE EM UMA PROPOSTA METODOLÓGICO-PROCEDIMENTAL PARA PESQUISA NO CAMPO DA CULTURA ESCRITA E IMBRICAMENTO COM OS PROCESSOS DE ESCOLARIZAÇÃO}

A articulação entre os construtos teóricos proposta até aqui e as implicações das discussões de identidade à luz dessas mesmas articulações, ao mesmo tempo em que nos confortam - porque encontramos nelas elementos para construir inteligibilidades para estudos acerca da cultura escrita e dos processos de ensino e aprendizagem -, inquietam-nos porque não temos delas modelos analíticos para aportar nossas pesquisas. Desse desconforto nasceu o presente artigo, amparado nas especificidades da Linguística Aplicada no que respeita a sua condição de interpenetração entre diferentes ciências, entre diferentes abordagens (MOITA LOPES, 2006; SIGNORINI, 1998).

Na busca por sossegar nossas inquietações, propomos, nesta seção, um desenho ainda preliminar de nossa vontade de construção de caminhos analíticos atentos às especificidades dos construtos teóricos que 
convidamos ao simpósio proposto aqui, mas ansiosas por materializar esse simpósio de um modo mais efetivo, que permita aos pesquisadores da área vislumbrar pontos de apoio para os seus fazeres de pesquisa, sobretudo considerando a prevalência de estudos de caso de tipo etnográfico, nos quais os instrumentos de geração de dados caracterizam-se por demandar posturas interpretativas e não posturas explicativas passíveis de se submeter ao escrutínio da replicação e da verificabilidade (MASON, 1996).

É nossa vontade poder analisar representações, concepções, falares, posicionamentos e afins sem ter de lançar mão de teorizações acerca de análise do discurso, seja qual for a vertente sob a qual essa mesma análise se processe, porque não é o discurso em si mesmo que nos interessa, mas o encontro dos sujeitos com a outridade por meio da modalidade escrita da língua e as implicações da constituição da subjetividade derivadas desse encontro (VIGOTSKI, 2000 [1978]) no que respeita a representações de mundo sobre as quais cabe aos processos de escolarização incidir na horizontalização de que tratam Kalantzis e Cope (2006). Eis nossa atenção à forma como os processos de ensino e aprendizagem da modalidade escrita da língua são engendrados nesses mesmos encontros, tanto quanto nossa atenção aos impactos depreensíveis em se tratando da intrassubjetividade - agora, as relações entre os universos interpsicológico e intrapsicológico, propostas por Vigotski (2000 [1978]). Desse modo, não são categorias analíticas do discurso que nos interessam, mas categorias metodológico-procedimentais que não coloquem a materialidade discursiva como foco, mas a compreendam como instrumento psicológico de mediação simbólica por meio do qual acontece o encontro, o que incide sobre as representações de mundo tal qual menção anterior. Enfim, é a Linguística do encontro que nos interessa e não a análise discursiva no âmbito da Linguística.

Assim, assumindo o risco de uma proposição dessa ordem, passamos a delinear, no espaço desta seção, uma proposta ainda inicial, de abordagem metodológico-procedimental para pesquisas, sobretudo no âmbito da cultura escrita e dos processos de ensino e de aprendizagem de língua materna, nas esferas acadêmica e escolar, em estudos de caso de tipo etnográfico (ANDRÉ, 2008 [2005]; YIN, 2005; DURANTI, 2000). A base de apoio para essa proposição são encaminhamentos de Hamilton (2000), já bastante conhecidos na área. Partindo do quadro proposto pela autora, arriscamos uma ressignificação do que entendemos serem categorias analíticas, fazendo-o à luz da proposição de simpósio conceitual já especificada ao longo deste artigo.

Inicialmente importa tomarmos o quadro proposto por Hamilton (2000). Ei-lo tal qual se apresenta.

Quadro 1 - Elementos constitutivos das práticas e dos eventos de letramento.

\begin{tabular}{|l|l|}
\hline $\begin{array}{l}\text { Elements visible within literacy events } \\
\text { (These way be captured in photographs) }\end{array}$ & $\begin{array}{l}\text { Non-visible constituents of literacy practices } \\
\text { (These way only be inferred from photographs) }\end{array}$ \\
\hline $\begin{array}{l}\text { Participants: the people who can be seen to be } \\
\text { interacting with the written texts. }\end{array}$ & $\begin{array}{l}\text { The hidden participants - other people, or groups of } \\
\text { people involved in the social relationships or } \\
\text { producing, interpreting, circulating and otherwise } \\
\text { regulating written texts. }\end{array}$ \\
\hline $\begin{array}{l}\text { Settings: the immediate physical circumstances in } \\
\text { which the interaction takes place. }\end{array}$ & $\begin{array}{l}\text { The domain of practice within which the events takes } \\
\text { place and takes its sense and social purpose. }\end{array}$ \\
\hline $\begin{array}{l}\text { Artefacts: the material tools and accessories that are } \\
\text { involved in the interaction (including the texts). }\end{array}$ & $\begin{array}{l}\text { All the other resources brought to the literacy practice } \\
\text { including non-material values, understandings, ways of } \\
\text { thinking, feeling, skills and knowledge. }\end{array}$ \\
\hline $\begin{array}{l}\text { Activities: the actions performed by participants in the } \\
\text { literacy event. }\end{array}$ & $\begin{array}{l}\text { Structured routines and pathways that facilitate or } \\
\text { regulate actions; rules of appropriacy and eligibility } \\
\text { - who does/doesn't, can/can't engage in particular } \\
\text { activities. }\end{array}$ \\
\hline
\end{tabular}

Fonte: Hamilton (2000a, p. 17).

O desenho desse quadro inquieta-nos em razão de não encontrarmos nele verticalizações que entendemos necessárias para a construção das inteligibilidades que nos são caras, tanto quanto no que tange à forma linear sob a qual parece se erigir. A questão mais relevante nesta proposição de ressignificação é partir do encontro instituído pela modalidade escrita da língua, encontro situado, que se dá em uma esfera específica da 
atividade humana, com imbricamentos de tempo e espaço específicos, o que nos leva também ao conceito bakhtiniano de cronotopo. Assim, importa-nos a proposição da centralidade do quadro - que ressignificamos sob a forma de diagrama com movências em dialogia - no encontro, com destaque à esfera da atividade humama em que esse encontro se dá, tanto quanto ao cronotopo em que se historiciza.

O encontro implica interactantes, nomeação que preferimos a participantes, entendendo fundamental haver a expansão desse olhar, de modo a contemplar o continuum dessa mesma condição de participação, o que nos remete a Kramsch (1998) e suas reflexões sobre as condições de insider e outsider, a que já fizemos menção, mas com a ressalva de que essas condições não sejam tomadas em uma abordagem dicotômica apriorística, mas sejam analisadas no espectro de movências que caracterizam a constituição da identidade na relação com a outridade. Entendemos, ainda, que, antes da reflexão sobre os participantes, importa uma olhar analítico sobre o encontro, em se tratando das razões que o movem e do conceito bakhtiniano de cronotopo (BAKHTIN, 2003 [1979]; BAKHTIN, 1998 [1975]) que potencialmente o engendra. Ainda em se tratando do conceito de participantes que nomeamos interactantes, dado o propósito da ressignificação que nos move, importa tematizar a [des] simetria das relações entre esses mesmos participantes, quer se trate da presença de interlocutores mais experientes (VIGOTKSKTI, 2000 [1978]), questão implicada na hibridização entre letramentos globais e locais (STREET, 2003) e a horizontalização das vivências com a escrita (KALANTZIS; COPE, 2006), quer se trate de [des]simetrias movidas pelas configurações de natureza econômica, o que remete a discussões de disponibilidade e acessibilidade propostas por Kalman (2003) e presentes em Britto (2012).

No que respeita aos contextos e domínios, entendemos importante ressignificar esse olhar de modo a contemplar as diferentes esferas da atividade humana já mencionadas. Entendemos problemático o conceito de contexto, dadas as múltiplas significações e desdobramentos conceituais que o termo tem na literatura da área, do que, à guisa de exemplo, vale mencionar a Linguística Textual e a Sociolinguística Interacional, âmbitos nos quais seguramente a noção de contexto é substancialmente distinta do que entendemos ser o enfoque de estudos que nos interessa enfatizar. Do mesmo modo, a noção de domínios, que também aparece em Barton (1994), parece-nos evocar insularizações antropológicas, circunscrevendo-se ao âmbito da cultura sem dar conta com maior elasticidade da dinamicidade da ação humana em sua inserção ideológica. Entendemos que o conceito de esfera da atividade humana (VOLÓSHINOV, 2009 [1929]; BAKHTIN, 2003 [1979]) - sobretudo pela presença da noção de atividade - parece-nos mais efetivamente produtivo para a análise dos encontros, uma vez que traz consigo implicações ideológicas - ideologia entendida, aqui, como “[...] conjunto de valores e de ideias que se constitui na interação verbal de diferentes sujeitos pertencentes a diferentes grupos socialmente organizados na história concreta" (GEGE, 2009, p. 60) -, tanto quanto implicações de organização da multiforme atividade humana que justifica os diferentes encontros.

Já a noção de artefato, em nossa compreensão, implica desdobramentos que talvez constituam o maior desafio dessa proposição de ressignificação categorial. Trata-se, aqui, da materialização da modalidade escrita da língua nos encontros instituídos pela linguagem. A noção de artefato, em nossa compreensão, demanda verticalização, no sentido de precisar mais efetivamente distinções entre o que entendemos ser passível de tratamento como suporte e o que entendemos remeter ao âmbito da textualização efetiva: o plano da materialidade verbal consolidada na modalidade escrita da língua. Importa, aqui, discutir a tessitura textual, os recursos fraseológicos e gramaticais agenciados nos diferentes projetos de dizer, as estratégias do dizer de que trata Geraldi (1997 [1991]). Eis a discussão seguramente mais trabalhosa porque desafiadora no sentido de não projetar essa mesma materialidade para além de sua condição de instrumento psicológico de mediação simbólica. Nossa proposta, tal qual o diagrama integrado a seguir visibiliza, é analisar a materialidade textual, no amplo espectro do encontro, lançando mão de teorizações da Linguística Textual e das teorias da enunciação, ressignificando-as porque as tomando no âmbito do encontro e não nos limites no texto - tal qual tende a fazer a LT - nem nos limites da subjetividade, tal qual tendem a fazer algumas teorizações no campo da enunciação, a exemplo do ideário benvenistiano. Quando ao suporte físico em que essa materialidade tem lugar - a noção de artefato propriamente dita -, teria lugar no amplo espectro de reflexões quer sobre a esfera da atividade humana, quer no delineamento nomeado o ato de dizer e as estratégias linguísticas agenciadas nos projetos de dizer via escrita.

E, por fim, o conceito de atividade, os que-fazeres com a modalidade escrita da língua: optamos por analisar as atividades no âmbito do conceito de esfera da atividade humana. Nesse recorte, interessam-nos historicidades de tais atividades, tanto quanto propósitos que as engendram e formas como se institucionalizam na esfera em estudo. 
Arriscamos, assim, uma proposta de ressignificação do quadro de Hamilton (2000), mantendo, mas tentando expandir, suas categorias analíticas. Trata-se de uma proposição que se erige à luz do simpósio conceitual que propusemos ao longo deste artigo. Vamos, pois, ao diagrama em intersecção: tal qual Hamilton (2000), foco nos eventos de letramento, situações visíveis em que o encontro mediado pela escrita se dá, e foco nas práticas de letramento, depreensíveis à luz dos eventos. Na parte do diagrama correspondente aos eventos, mencionamos recursos de pesquisa por meio dos quais os dados para análise possam ser gerados; trata-se, porém, de indicadores ainda a carecer expansão. Eis, na figura 1, o que estamos nomeando como diagrama integrado.

Figura 1 - Diagrama integrado: inter-relação entre eventos e práticas de letramento como modelo analítico

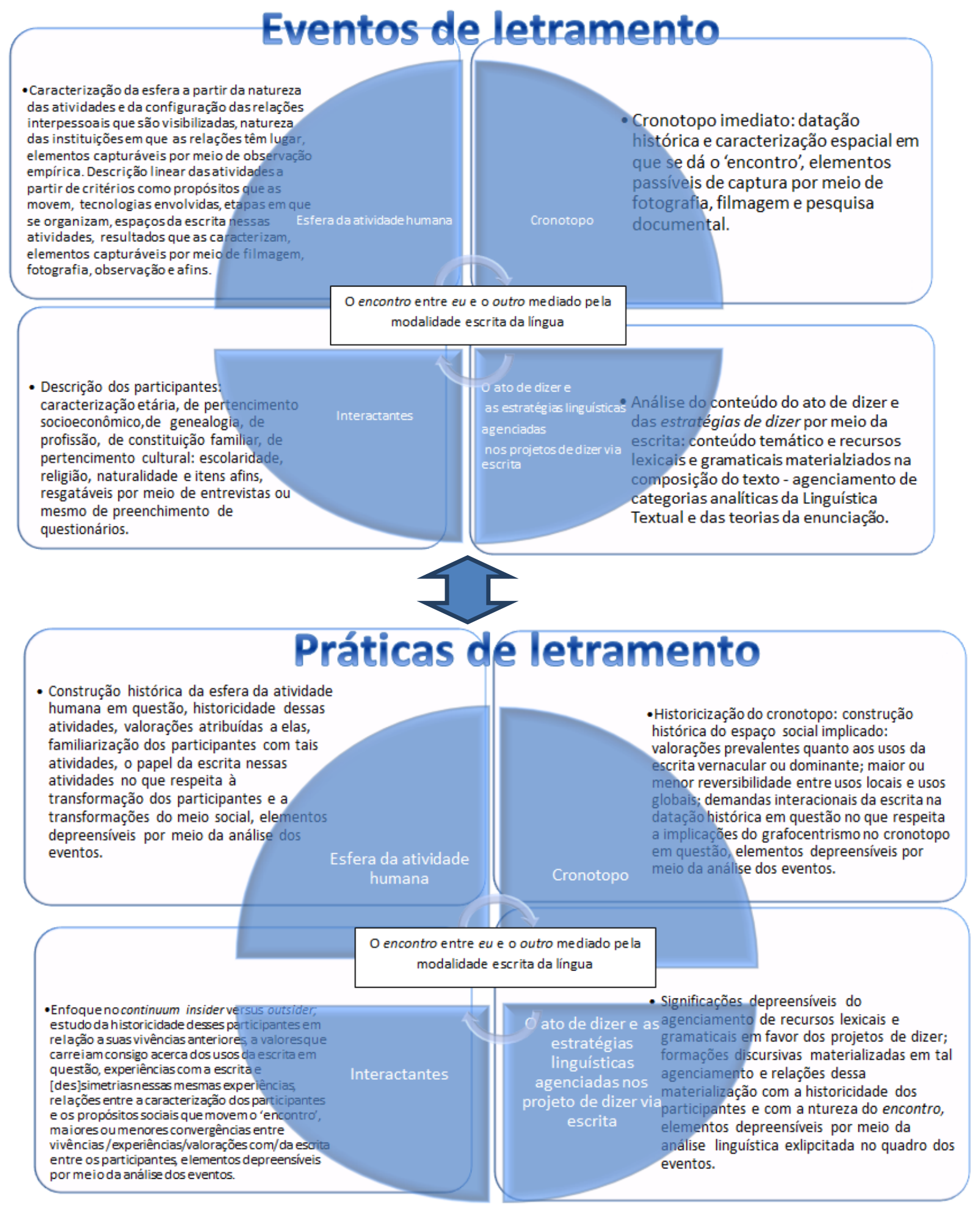

Fonte: Criação das autoras 
A proposição das categorias analíticas especificadas neste Diagrama integrado objetiva facultar condições de geração e análise de dados em se tratando de pesquisas no campo da cultura escrita, com destaque aos processos de escolarização, mas não circunscritas a eles. O foco, reiteramos, é o encontro de interactantes por meio da modalidade escrita da língua, o qual se institui em uma esfera da atividade humana específica, implicando cronotopia e se materializando pelo ato de dizer que requer agenciamento de estratégias de dizer via escrita. Esse encontro se deixa ver nos eventos, capturáveis por meio de recursos de pesquisa específicos; tendo capturado os eventos, depreendem-se as práticas, que carreiam historicizações as quais demandam um olhar interpretativo zeloso.

\section{CONSIDERAÇÕES FINAIS}

Este artigo construiu-se tendo como eixo a proposição de um simpósio entre construtos teóricos ancorados na psicologia da linguagem, na filosofia da linguagem e na antropologia da linguagem, os quais compartilham entre si concepções de sujeito não isomórficas, mas em relação dialógica, porque focadas na historicidade humana, na inserção social e no pertencimento cultural dos homens. Compartilham, ainda, concepções de língua tomadas no uso, na interação, no encontro. Identificando-nos com esses construtos teóricos em nossos estudos e pesquisas, não encontramos, porém, neles modelos analíticos que nos permitam empreender nossos processos de análise de dados gerados em pesquisas no campo da cultura escrita no imbricamento com os processos de escolarização. Na tentativa de encontrar respostas para as dificuldades com que vimos convivendo nesse embate de não querer abrir mão da lógica sob a qual se instituem esses ideários que nos são caros e não encontrar neles elementos mais específicos para nossos movimentos analíticos, arvoramo-nos à proposta que aqui se consolida, objetivando interlocução com a comunidade científica ocupada desses temas, no afã de checar possibilidades e limitações desta proposição. Fica o risco e o convite ao diálogo.

\section{REFERÊNCIAS}

ANDRÉ, Marli Eliza Dalmazo Afonso de. Estudo de caso em pesquisa e avaliação educacional. 3. ed. Brasília: Liber Livro Editora, 2008 [2005].

BAKHTIN, Mikhail. Estética da criação verbal. São Paulo: Martins Fontes, 2003 [1979].

BAKHTIN, Mikhail. Questões de literatura e de estética - a teoria do romance. São Paulo: UNESP; Hucitec, $1998[1975]$.

BARTON, David. Literacy - an introduction to the ecology of written language. Cambridge, MA: Brackwell, 1994.

BAUMAN, Zygmunt. Identidade. Rio de Janeiro: Zahar, 2006.

BRANDIST, Craig. Repensando o Círculo de Bakhtin. São Paulo: Contexto, 2012.

BRITTO, Luiz Percival Leme. Inquietudes e desacordos. Capinas, SP: Mercados das Letras, 2012.

CERUTTI-RIZZATTI, Mary Elizabeth. Letramento: uma discussão sobre implicações de fronteiras conceituais. Educação e sociedade, Campinas, v. 33, n.18, p. 291-305, jan./mar. 2012.

DUARTE, Newton. Vigotski e o aprender a aprender. 3. ed. Campinas, SP: Autores Associados, 2004.

DURANTI, Alessandro. Antropología Linguística. Madrid: Cambridge University Press, 2000.

FARACO, Carlos Alberto. O estatuto da análise e interpretação dos textos no quadro do círculo de Bakhtin. In: GUIMARÃES, Ana Maria de Mattos; MACHADO, Anna Raquel; COUTINHO, Antónia. (Orgs.). O interacionismo sociodiscursivo: questões epistemológicas e metodológicas. Campinas, SP: Mercados da Letras, 2007.

GEGE - Grupo de Estudos dos Gêneros do Discurso. Palavras e contrapalavras: glossariando conceitos, categorias e noções de Bakhtin. São Carlos: Pedro \& João Editores, 2009.

GERALDI, João Wanderley. Alfabetização e letramento: perguntas de um alfabetizado que lê. s.l.: s.n. [s.d.]. 
GERALDI, João Wanderley. Portos de passagem. 4. ed. São Paulo: Martins Fontes, 1997 [1991]. . A aula como acontecimento. São Paulo: Pedro e João Editores, 2010 a. . Ancoragens - Estudos Bakhtinianos. São Carlos: Pedro e João Editores, $2010 b$. ; BENITES, B.; FICHTNER, M. Transgressões convergentes: Vigotski, Bakhtin e Bateson. Campinas, SP: Mercado das Letras, 2007.

HALL, Stuart. A identidade cultural na pós-modernidade. 7. ed. Tradução de Tomaz Tadeu da Silva, Guaracira Lopes Louro. São Paulo: Editora DP\&A, 2002.

HAMILTON, Mary. Expanding the new literacy studies: using photographs to explore literacy as social practice. In: BARTON, David; HAMILTON, Mary; IVANIC, Roz (Orgs.). Situated literacies. London: Routledge, 2000.

HEATH, Shirley Brice. What no bedtime story means: narrative skills at home and school. In: DURANTI, A. (Org.). Linguistic Anthropology: a reader. Oxford: Blackwel, 2001 [1982]. p. 318-342.

IVANIC, Roz. Writing and Identity: the discoursal construction of identity in academic writing. Amsterdam: John Benjamins, 1998.

KALANTIZIS, Mary; COPE, Bill. Multiliteracies. London: Routledge, 2006.

KALMAN, Judith. El acesso a la cultura escrita: la participación social y la apropriación de conocimientos en eventos cotidianos de lectura y escritura. Revista mexicana de investigación educativa, vol.VIII, n. 17, p. 3766, enero/abril 2003.

KLEIMAN, Angela B. (Org.). Modelos de letramento e as práticas de alfabetização na escola. In: Os significados do letramento: uma nova perspectiva sobre a prática da escrita. Campinas, SP: Mercado dos Letras, 2001 [1995]. p.15-64.

KRAMSCH, Claire. Language and Culture. New York: Oxford University Press, 1998.

LILLIS, Theresa M. Student writing: access, regulation, desire. Londres: Routledge, 2001.

MASON, Jennifer. Qualitative researching. London: SAGE Publications, 1996.

McLAREN, Peter. Culture or canon? Critical pedagogy and the politics of literacy. Miami: s.n., 1987.

MOITA LOPES, Luiz Paulo de. Linguística Aplicada e vida contemporânea: problematização dos construtos que têm orientado a pesquisa. In: Parábola Editorial, 2006. . (Org.). Por uma linguística indisiciplinar. São Paulo:

PONZIO, Augusto. Procurando uma palavra outra. São Carlos: Pedro e João Editores, 2010.

SIGNORINI, Inês. Do Residual ao múltiplo e ao complexo: o objeto da pesquisa em linguística aplicada. In: ; CAVALCANTI, Marilda C. (Org.). Linguística Aplicada e transdisciplinaridade. Campinas/SP:

Mercado das Letras, 1998.

STREET, Brian. Literacy in theory and practice. Cambridge: CUP, 1984.

Practices and Literacy Myths. In : SALJO,R (Ed.). The written world: studies in literate thought and action. Berlim: Springer-Verlag, 1988.

Abordagens alternativas ao letramento e desenvolvimento. Teleconferência Unesco Brasil sobre 'letramento e diversidade', outubro de 2003.

VIGOTSKI. Lev Semenovich. A formação social da mente. São Paulo: Martins Fontes, 2000 [1978].

VOLÓSHINOV, Valentín Nikoláievich. El marxismo y La filosofia del lenguaje. Buenos Aires: Ediciones Godot, 2009.

YIN, Robert K. Estudo de caso: planejamento e métodos. 3. ed. Porto Alegre: Bookman, 2005.

Recebido em 14/11/12. Aprovado em 15/01/13. 